\title{
Descendência e aliança no espaço tuyuka. A noção de nexo regional no noroeste amazônico
}

\author{
Aloisio Cabalzar \\ Mestre em Antropologia Social - USP e assessor do Programa \\ Rio Negro do ISA
}

\begin{abstract}
RESUMO: Considerando a situação atual das pesquisas sobre organização social no noroeste amazônico, este ensaio propõe uma interpretação de como relações baseadas na descendência patrilinear e na aliança estão articuladas e organizadas espacialmente, para o caso dos Tuyuka do alto Tiquié (bacia do Uaupés). O modelo que surge está fundamentado em distinções entre duas formas de grupo local, que compõem um nexo regional formado por centro e periferia. Este modelo permite vislumbrar um sistema social uaupesiano com áreas em que predominam valores baseados no agnatismo, na língua comum e na exogamia, e como estas áreas estão conectadas entre si.
\end{abstract}

PALAVRAS-CHAVE: índios Tuyuka - organização social, índios Tuyuka - Tukano Oriental, rio Tiquié - Sistema Uaupés, Pirá-paraná - noroeste amazônico.

O objetivo deste artigo é sugerir uma interpretação da organização social tuyuka, privilegiando a ordenação espacial supralocal. Exploro a idéia de nexo regional para os Tuyuka do alto rio Tiquié.

Os Tuyuka são um dos 16 grupos linguíísticos Tukano Oriental, família lingüística localizada no noroeste amazônico, na região da fronteira BrasilColômbia, alto rio Negro. Mantêm relações mais estreitas (matrimoniais, rituais e comerciais) com os Tukano, Bará, Makuna e Desana. Atualmente os Tuyuka moram no alto Tiquié (entre os Tukano à jusante, os Bará à 
montante, os Hupd $U$ Maku nos igarapés da margem norte e os Makuna nos da margem sul) e no igarapé Inambú, afluente do rio Papuri. Estes dois conjuntos de grupos locais tuyuka, embora próximos geograficamente, mantêm poucos contatos entre si, havendo algumas diferenças lingüísticas (lexicais e no ritmo da fala).

Dentre os traços comuns que caracterizam os diversos povos Tukano Orientais, podemos destacar: a mitologia, especialmente a relativa à origem e trajetória comum da Cobra Ancestral, que concebeu todos estes povos; os rituais de oferecimento (dabucuri) e cerimônias com os "cantos dos velhos", cantos que são semelhantes em toda a área do Uaupés; uma perspectiva geográfica baseada nos rios; uma subsistência baseada na pesca e na agricultura da mandioca brava; a maloca como moradia comum e modelo de concepção da vida social e do cosmos; concepções e práticas xamânicas específicas. No que diz respeito à organização social propriamente dita, observa-se que a estrutura de cada grupo de descendência exogâmica é baseada em um conjunto de sibs nomeados, localizados - ou com uma viva idéia de um passado unido pela co-residência-, e hierarquizados entre si. Nesta área sócio-cultural dominada pelos grupos Tukano Orientais ${ }^{1}$ (os Maku vivem nas regiões de interflúvio e não mantêm relações de aliança por casamento com os TUKANO) ocorre uma coincidência, embora não universal, entre unidade lingüística e unidade de descendência exogâmica, da qual vem a regra de exogamia lingüística; ou seja, a língua é uma referência comum na definição do grupo de descendência exogâmico. Ocorre ainda uma forte tendência à exogamia local e à virilocalidade.

Neste texto pretendo contribuir com algumas discussões relevantes especificamente ao estudo da organização social no noroeste amazônico, como a relação entre espaço geográfico e hierarquia e as noções de descendência e de afinidade como meios de inteligibilidade do socius e referência na prática das relações sociais, sobretudo no âmbito de grupos locais próximos (nexo regional).

No noroeste amazônico, os princípios da descendência e da afinidade concorrem e se alternam na constituição de grupos locais ${ }^{2}$. Embora a descendência seja o princípio de maior valor conceitual para os Tuyuka, é 
evidente a importância das relações de afinidade como estruturadoras de certos arranjos locais ${ }^{3}$.

Já se tornou clássica a noção de grupo de descendência localizado, consensual entre os estudiosos do noroeste amazônico, na qual as fronteiras do grupo local coincidem com as de um grupo de descendência, em geral um sib ou segmento deste. Este ensaio pretende problematizar a organização social além do grupo local, no âmbito do nexo regional, investigando formas específicas de ocupação do espaço geográfico e as concepções tuyuka correspondentes.

O nexo regional é formado por um conjunto de grupos locais conectados por relações políticas, rituais e de trabalho; trata-se de um ambiente em que trocas de informações, bens e visitas são mais intensas. Essas relações definem-se com base na descendência e na aliança, ou seja, baseadas no parentesco agnático ou na relação entre afins. São formas de relacionamento fundamentalmente distintas, cada qual com suas próprias regras e maneiras de agir. No caso específico dos povos Tukano Orientais, as relações agnáticas possuem conotações hierárquicas (embora não reveladas em todos os contextos) e lingüísticas nítidas.

Com base em dados etnográficos, argumento que o domínio territorial de um grupo de descendência exogâmico sofre inflexões resultantes das alianças, criando dois ambientes sociais (centro e periferia) marcados geograficamente. Este dualismo territorial é a síntese de gradações que vão do parentesco agnático às alianças próximas, da identidade lingüística ao multilingüismo, da hierarquia à igualdade.

\section{Discussão teórica: sentidos do nexo regional}

A proximidade espacial, algumas vezes caracterizada pela falta de fronteiras nítidas e por áreas em que se observa uma sobreposição de dois ou mais grupos de descendência exogâmicos ${ }^{4}$, e as intensas trocas matrimoniais, o intercâmbio comercial e ritual e as afinidades culturais tornam difícil definir uma unidade social no noroeste amazônico. 
Nas etnografias a respeito destes povos há sugestões de diferentes critérios para a definição de grupos sociais. Goldman (1963) aplica a noção de tribo à unidade linguística (formada por três fratrias cubeo que trocam mulheres entre si), mas é a fratria que tem mais sentido social (ver nota 19). Distintamente, Sorensen (1967) chama a atenção para a associação que fazem os índios entre língua e exogamia, e usa o termo tribo para designar uma fratria de sibs que falam a mesma língua (ou seja, um grupo exogâmico). Jackson (1983) segue o caminho aberto por Sorensen, mas substitui o termo "tribo" por "grupo lingüístico". Christine Hugh-Jones (1979 a) é que formula o modelo mais abrangente, baseado na noção de grupo de descendência exogâmico, abrindo mão do fator lingüístico, em razão da sua não validade a todas as situações uaupesianas.

Embora a língua seja um parâmetro muito valorizado na categorização do universo social, a unidade linguística não coincide necessariamente com as fronteiras de um grupo de descendência exogâmico. Neste sentido, observamos não só a exceção clássica dos Cubeo (Goldman, 1963), que estão divididos em três fratrias exogâmicas que falam a mesma língua e trocam esposas entre si, mas também a precariedade deste critério em outros contextos. No caso Barasana/Taiwano (Hugh-Jones, 1979 b: 24) ${ }^{5}$, que falam a mesma língua, com pequenas diferenças valorizadas socialmente, a distinção nativa não coincide com a do observador. Existem ainda situações em que ocorre a dominação de uma língua sobre outras, como pode ser observado na "tukanização" dos Tariana e Arapaço no médio Uaupés (entre Ipanoré e Iauareté), e da uniformização dos dialetos makuna (visível na comparação dos dados de Koch-Grünberg (1913) com as afirmações recentes de Århem, 1981).

Portanto, existe um problema metodológico na definição de um grupo social com fronteiras bem marcadas nesta região. A preocupação em não empregar noções clássicas da Antropologia Social, tais como tribo e mesmo sociedade, para designá-los, justifica-se uma vez que estas noções supõem a existência de continuidade territorial, língua e cultura particular. Abrir mão destes conceitos é um primeiro passo, permanecendo a questão sobre quais outros seriam mais adequados. A proposta de Christine Hugh-Jones, baseada 
na noção de grupos exogâmicos compostos por sibs estreitamente ligados pela descendência comum e pela complementação funcional ${ }^{6}$, representa mais um passo na busca de definições operacionais. Esta visão da estrutura social do Uaupés como um sistema formado por grupos que trocam mulheres é alternativa àquela que privilegia a unidade linguiística. Apesar de nenhuma delas estar associada a fronteiras territoriais bem demarcadas, ambas valorizam a contigüidade espacial do grupo de descendência, necessária tanto para a continuidade linguiística (menos provável em grupos locais isolados da região de predomínio de sua língua) como para a complementação funcional.

Mais recentemente, não apenas a noção descendência mas também a de aliança passou a ser privilegiada na análise dos grupos sociais na região do Uaupés e, do ponto de vista sociológico, como princípios estruturais à organização social. Kaj Århem, antropólogo sueco que pesquisou os Makuna (grupo vizinho aos Tuyuka do alto Tiquié e alto igarapé Castanha), é o que leva mais adiante esta proposta e toma a aliança como um problema no entendimento dessas organizações sociais. Por isso, é importante uma abordagem mais atenta de algumas de suas idéias. $\mathrm{O}$ autor incorpora a aliança em seu modelo principal da organização social makuna; mais do que isto, privilegia este princípio na descrição dos grupos sociais. Para tanto, começa por demonstrar que os Makuna se casam com afins próximos (espacialmente) na grande parte dos casos e estabelecem com eles relações de intensa solidariedade.

Desenvolvendo uma idéia de Christine Hugh-Jones (1979 a: 97), ele diferencia três tipos básicos de casamento: (1) aquele que ocorre entre grupos próximos, entre os quais há relações de reciprocidade generalizada e cooperação econômica, política e ritual; neste caso o casamento não exige a retribuição imediata de uma mulher para o grupo que cedeu uma; (2) a troca de irmãs, que se verifica entre grupos não muito próximos e, portanto, um dos grupos só cede uma mulher tendo em vista receber outra logo; (3) por último, o casamento por captura, característico entre grupos distantes e hostis, quando a mulher é tomada ao ser raptada em uma expedição de homens planejada com este objetivo. Århem propõe as seguintes associações (1981: 149): 


\begin{tabular}{c|c|c} 
Reciprocidade Generalizada & Reciprocidade Balanceada & Reciprocidade Negativa \\
“GIFT MARRIAGE” & TROCA DIRETA & RAPTO DA NOIVA \\
aliados próximos & aliados distantes ou afins não relacionados
\end{tabular}

Distância espacial e dos afins

O autor afirma que o ideal de casamento por captura (muitas vezes colocado em prática) incorpora uma concepção da sociedade baseada na descendência: "It derives from the ideological opposition between kin and affines, in which agnatic kinship is equated with friendship and spatial proximity as opposed to affinity, which represents hostility, distrust and spatial remoteness" (Århem, 1981: 153). Porém, Århem se desvia desta caracterização da organização social makuna, afirmando que apenas uma minoria dos casamentos ocorre por captura da mulher; sendo bem menos numerosos aqueles realizados entre pessoas próximas espacial e genealogicamente. Assim como o rapto da noiva reforça a ideologia da descendência, os casamentos do primeiro tipo revelam a importância do sistema de aliança makuna (ibid.: 180).

A formação de nexos endogâmicos, constituídos por grupos residenciais próximos espacialmente e que estabelecem relações econômicas, políticas, rituais e matrimoniais estreitas, é favorecida pelo ideal de casamento com primos cruzados bilaterais reais e pela preferência efetiva em realizá-lo na mesma linha dos pais ${ }^{7}$. A necessidade de manter tais relações (de repetição de alianças) tornaria secundárias questões como o equilíbrio das trocas entre os grupos (em termos do número de mulheres dadas e recebidas) ou a discriminação entre diferentes primas cruzadas (patri-, matri- ou bilateral). O nexo endogâmico (chamado de grupo local) atuaria como grupo corporado em casos de conflitos com grupos distantes e, especialmente, no controle de suas mulheres. Uma ampla reciprocidade econômica, ritual e política - é verificada neste âmbito ${ }^{8}$. 
Aqui é necessário descrever a distinção que este autor faz entre "grupo residencial" e "grupo local". O primeiro corresponde a uma moradia (uma maloca ou casa menor) e é constituído, em geral, por um segmento mínimo de um $s i b^{9}$. Trata-se de uma estrutura agnática tipicamente superficial (Århem, 1981: 226). Esta estrutura tende a passar por um ciclo de desenvolvimento curto, caracterizado inicialmente pela família nuclear (o casal e seus filhos pequenos), depois estes crescem, casam-se, seu pai morre e a estrutura fraternal tende a se fissionar, especialmente por causa da ausência da figura paterna (ibid.: 231). Observa-se entre os Makuna uma marcada limitação do agnatismo enquanto relação capaz de manter grupos residenciais coesos, e apenas $38 \%$ dos irmãos reais convivem na mesma casa (ibid.: 249, quadro 32).

Os grupos residenciais, tal como definidos por Århem, são distintos dos povoados existentes hoje em grande parte da bacia do Uaupés, bem como das grandes malocas do passado, compostas de mais de dez grupos domésticos (como descritos por fontes do final do século passado e início deste, por exemplo: Rice, 1910: 695 e Koch-Grünberg, 1967). No caso makuna, o autor considera duas casas separadas apenas pelo rio formando grupos residenciais distintos. São mencionados alguns grupos residenciais de composição mais complexa, mas são poucos e pequenos, na média a população é de 12,5 pessoas, ou seja, uma maloca de dois ou três fogos.

Por sua vez, o grupo local é um nexo formado por alguns grupos residenciais (os três mencionados pelo autor são formados por cinco, sete e nove grupos residenciais). Esta unidade não corresponde a uma categoria nativa específica, sendo definida pelo observador. Constituem unidades políticas, com a presença de lideranças (o que se verifica para dois dos três grupos locais enfocados); no entanto, é a rede de alianças matrimoniais que consolida esta estrutura (Århem, 1981: 241 e 244-5).

Resumindo, no modelo final proposto por Århem, o princípio da descendência opera enquanto estruturador apenas no âmbito dos grupos residenciais; além dessa esfera, as relações inter-comunitárias são orientadas pelas redes de aliança. Portanto, ambos os princípios são funcionais, mas 
em âmbitos espaciais distintos. Em sua etnografia, Århem apresenta dados objetivos (estatísticas, números absolutos, genealogias e mapas detalhados), tornando mais transparentes suas opções analíticas. Isto permite a comparação com organizações sociais de outras regiões do noroeste amazônico, como faremos mais abaixo em relação aos dados coletados junto aos Tuyuka.

Em trabalho mais recente (1989), Århem faz uma comparação entre os Makuna, os MAKU e as sociedades guianenses, e trata o material makuna como uma anomalia no contexto dos grupos Tukano Orientais. De acordo com o autor, se os $\mathrm{MAKU}^{10}$ se situam em um dos extremos do espectro de classificação social dos TuKANO, os Makuna constituiriam uma categoria intermediária entre estes dois pólos (1989: 11). Isto se deve, primeiro, ao fato dos Makuna não considerarem a regra da exogamia lingüística; segundo, porque não ocorre entre eles uma exogamia ampla, em sentido territorial, mas se restringem à exogamia da maloca.

Fica patente no trabalho de Århem que o número de casamentos endogâmicos ou exogâmicos determina em quais âmbitos a descendência ou a aliança predomina como princípio de sociabilidade. Como vimos, esse autor chega a falar de grupos corporados formados por casas ligadas por estreitas alianças, que ele chama de local alliance group e têm a função de controlar o principal recurso de produção e reprodução: as mulheres. Århem afirma que isto significa uma contradição da estrutura social makuna, visto que convive com uma ideologia da descendência. Stephen HughJones, por outro lado, mostra como estes dois princípios podem ser conciliados se analisados a partir da noção de societé à maison, de LéviStrauss. A abordagem unicamente estatística, critica Hugh-Jones, empobrece a representação da organização social, devendo-se considerar outros aspectos, como o ritual e o político. Hugh-Jones abre caminho para que a questão colocada por Århem seja explorada mais integralmente (HughJones, 1993 e 1995) ${ }^{11}$.

Nesses artigos, o autor utiliza dados barasana, desana e tukano ${ }^{12}$ do Tiquié e makuna. Afirma que a noção de descendência tem seus problemas e não se encaixa perfeitamente em certos idiomas nativos, além de não 
gerar, nesse contexto, corporações e uma dinâmica de segmentações como celebrizada na literatura africanista clássica. A caracterização que Århem faz dos Makuna é incorporada por Hugh-Jones, a de que no âmbito local (de cada maloca) verifica-se a exogamia e o agnatismo, ao passo que na esfera regional, que abrange várias malocas vizinhas, prevalecem a endogamia e a aliança. Neste ponto, ele também propõe uma aproximação com o material guianense (1993: 100).

Por outro lado, critica o etnólogo dos Makuna em sua ênfase na separação entre categorias ideais e prática social, sustentada a partir da constatação de uma disparidade entre o discurso makuna orientado por uma lógica da descendência e os dados empíricos, que demonstram a importância da aliança. Isto evidenciaria, para Århem (1989), uma anomalia makuna. Segundo S. Hugh-Jones, "far from being a deviation from some ideal, close marriage, local endogamy, a stress on consanguinity ${ }^{13}$ and an ethos of family and kinship are themselves part of an alternative ideal" (1993:105, 1995: 237).

Hugh-Jones caracteriza muito bem esses modelos, que considera diferentes, alternativos e complementares, ao associá-los aos rituais de iniciação (Casa $\mathrm{He}$ ) e de oferecimento de comida (food-giving house, ou dabucurí), respectivamente. "One, corresponding to the anthropologists' descent, emphasises hierarchy and a general masculine ethos and is most salient in the context of male initiation rites. The other conceptualisation is more egalitarian, is associated with a more feminine ethos and emphasises notions of kinship and consanguinity. Though especially pertinent to daily life, it too is given ritual expression during intercommunity exchange feasts" (1993: 97).

Nas cerimônias (dabucurís) que marcam essa associação regional de casas aliadas, solidárias e próximas geograficamente, os visitantes trazem e oferecem carne ou peixe moqueado e os anfitriões os recebem com grande quantidade de caxiri. $\mathrm{O}$ autor estabelece uma correspondência entre a relação convidados/anfitriões nos dabucurís e a relação entre os gêneros na vida cotidiana. Os que vêm de fora dão alimentos que são providos geralmente pelos homens (resultado da caça e da pesca) e os que os 
recebem oferecem produtos que são obtidos através do trabalho feminino, isto é, derivados da mandioca (caxiri e beijú, este consumido na refeição comum que é feita no final do ritual, antes da partida dos convidados) (Hugh-Jones, 1993: 101).

Já o idioma da descendência, da hierarquia entre parentes agnáticos, tem sua expressão máxima nos rituais de iniciação masculina, que diferem muito dos dabucurís. "He House is the antithesis of Food-giving House" (ibid.: 111). Na iniciação participam todos os homens do sib e é uma afirmação de sua autonomia. É orientado para o ancestral do grupo, verticalmente. $\mathrm{O}$ ambiente é outro, não de intimidade e comensalidade com os afins, mas de restrições severas: não entra caxiri, comida ou fogo, e tampouco ocorre uma refeição comum em seu encerramento. "The aftermath of the rite is characterised by a two-month long fast during which time the men avoid all contact with women" (ibid.).

Esse antagonismo entre estes dois idiomas, que marcam as relações sociais e que são celebrados separadamente nos dois rituais mencionados, fundamenta a organização social destes grupos. Mas não tem o caráter de anomalia se for pensado através da noção de société à maison, proposta por Lévi-Strauss. Segundo S. Hugh-Jones, “Lévi-Strauss suggests that the House represents a form of social organisation which might be described as standing halfway between lineal and cognatic principles of social organisation, conflating and transcending principles which are normally taken to be mutually exclusive” (ibid.: 98).

\section{Sistema regional tuyuka}

Essa discussão acerca da concorrência entre os princípios da descendência e da aliança e sua expressão espacial foi considerada ao organizar dados coletados em pesquisa de campo com os Tuyuka (Cabalzar, 1995). A proporção entre afins próximos e distantes (endogamia e exogamia) foi eleita como ponto de partida da análise.

Sistematizando informações referentes aos casamentos em cada grupo local tuyuka (no sentido dos povoados atuais, e não no definido por Århem) 
quanto à origem das cônjuges dos Tuyuka, procurei comparar com os dados a respeito dos Makuna (que são os únicos disponíveis, concernentes a este aspecto em particular, na bibliografia relativa aos grupos do Uaupés e Pirá-paraná).

Uma questão, porém, deve ser equacionada para um melhor prosseguimento deste ensaio: a pertinência de uma comparação entre os grupos locais ou povoados tuyuka atuais e os grupos residenciais makuna, dadas as diferenças assinaladas acima. A comparação se justifica pelas seguintes razões: (1) tanto a definição de grupo local tuyuka quanto a de grupo residencial makuna estão baseadas na noção de unidade local, separada geograficamente; (2) a coincidência desta unidade local com a maloca, como assinalado por Århem, também era observada entre os Tuyuka. O contato destes com os missionários salesianos, que aplicaram um programa sistemático e consciente de destruição das malocas (Nimuendajú, 1950; Béksta, 1988 e Cabalzar, 1999), levou ao seu gradual abandono a partir da década de 50 e dispersão dos grupos domésticos em casas separadas, formando os povoados atuais, como chamados regionalmente; (3) embora possa se atribuir à substituição da maloca pelo povoado uma flexibilização das relações sociais no âmbito local, é importante ressaltar que a unidade local, de uma forma ou de outra, mantém seu valor conceitual e prático (como unidade fundamental de solidariedade, comensalidade, produção, reprodução e distribuição).

Tendo feito esta consideração, segue a comparação entre os Tuyuka e os Makuna. Århem chegou à conclusão de que apenas o grupo residencial é constituído por homens relacionados agnaticamente (dificilmente os cunhados convivem em um mesmo sítio), sendo estruturado com base na descendência. Além dessa esfera, porém, prevalecem as relações de aliança. Assim, por exemplo, se tomarmos cinco malocas vizinhas, verifica-se que esta proximidade geográfica se deve à intensidade dos casamentos entre seus moradores. Segundo esse autor, no âmbito do grupo local (a associação entre várias malocas) ocorreriam 68\% dos casamentos (1981:151 e 1989: 11-3). De acordo com estes dados, os Makuna se casam especialmente com pessoas provenientes de locais próximos geograficamente. 


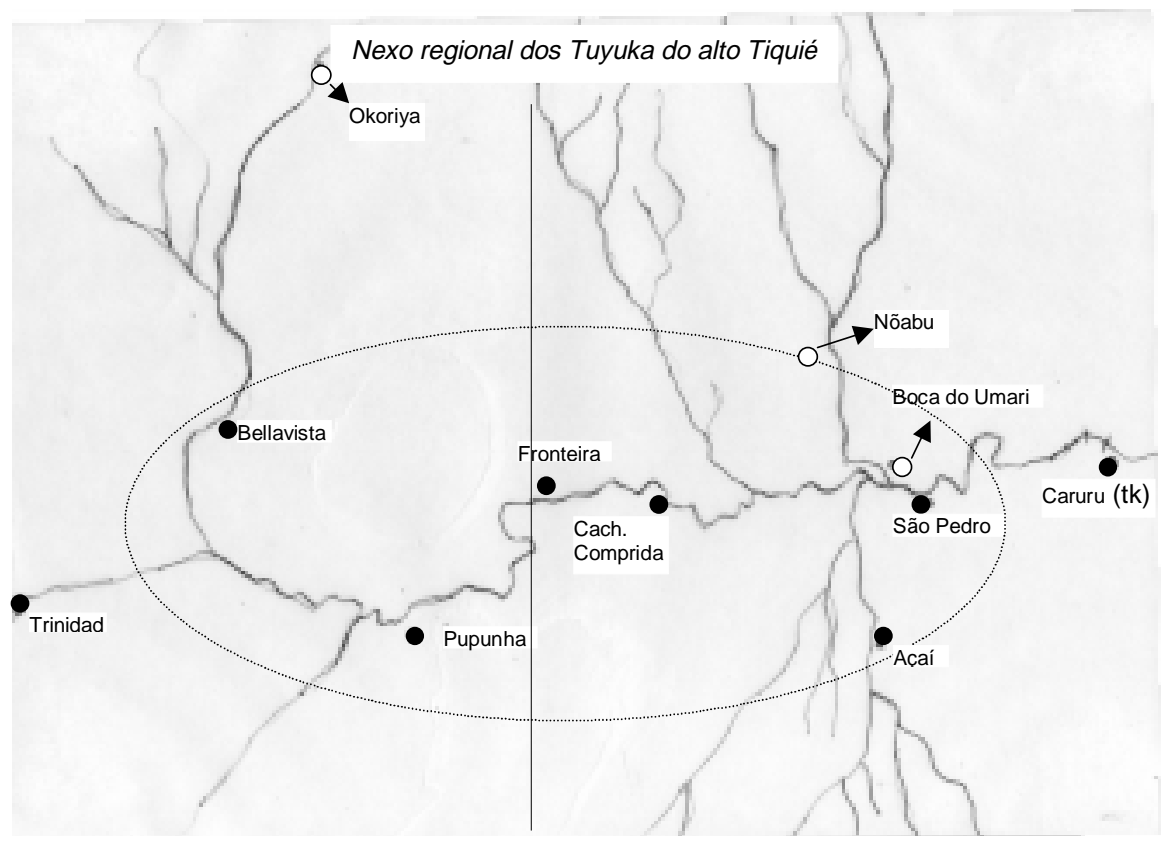

Mapa do alto Tiquié - detalhe da região de predomínio tuyuka (escala 1:100.000)

Este mapa mostra a região onde ocorre a maior concentração de povoados tuyuka no rio Tiquié. À jusante do povoado de Caruru está situada uma área de maioria tukano até Pari-Cachoeira e, daí para baixo, de tukano, desana e miriti-tapuya. A partir de Trinidad, o predomínio, nas cabeceiras do Tiquié, é dos bará; eles já estão presentes em grande número neste povoado e em Bellavista. Os povoados de Boca do Umari, Nõabu e Okoriya são Maku-hupd $U$. A linha que divide o mapa quase ao meio é a fronteira entre Brasil e Colômbia. A área definida pelo pontilhado corresponde à abrangência do nexo regional dos Tuyuka do alto Tiquié. $\mathrm{O}$ contorno dos rios e localização dos povoados foi feito com base em imagem de satélite. 
No caso dos Tuyuka do Tiquié, os números são diferentes. Ocorre que aproximadamente metade dos casamentos se efetua com grupos próximos e metade com distantes. Observando os dados povoado por povoado, a posição geográfica de cada um deles dentro do nexo regional tuyuka do alto Tiquié, e a localização dos afins em cada caso, constata-se a necessidade de elaborar, para esta situação específica, um modelo mais complexo, constituído por dois ambientes (ver Quadro 1 e Gráfico 1). Organizando assim os dados, fica clara uma maior incidência de casamentos próximos (com mulheres de grupos locais vizinhos ou do mesmo grupo local) entre aqueles povoados situados mais perifericamente no nexo regional tuyuka do alto Tiquié. Distintamente, os Tuyuka dos povoados situados na região central deste sistema praticavam casamentos mais diversificados e com mulheres de grupos locais mais distantes. Os grupos periféricos se conformaram melhor ao padrão makuna, com uma porcentagem alta de casamentos próximos, e os grupos centrais se afastaram desta definição, isto é, prevalecem aí casamentos mais ecléticos e distantes. Esta constatação é feita a partir do Quadro 1 e Gráfico 1 (os dados makuna foram retirados de Århem (1981: 151, quadro 10)). Os povoados de São Pedro, Bella Vista e Açaí (este último dividido entre tuyukae makuna) foram considerados grupos locais periféricos; ao passo que Cachoeira Comprida, Fronteira e Pupunha foram considerados centrais (ver Mapa).

\begin{tabular}{l|lcc}
\hline & & $\begin{array}{c}\text { afim } \\
\text { próximos }\end{array}$ & $\begin{array}{c}\text { afins } \\
\text { distantes }\end{array}$ \\
\hline Makuna & & 28 & 13 \\
Tuyuka & grupos locais centrais & 12 & 20 \\
& grupos locais periféricos & 29 & 21 \\
\hline
\end{tabular}

Quadro 1: Número de cônjuges dos Makuna e dos Tuyuka provenientes de afins residentes próximos (ou no mesmo grupo local) e distantes (ver porcentagens no gráfico abaixo. 


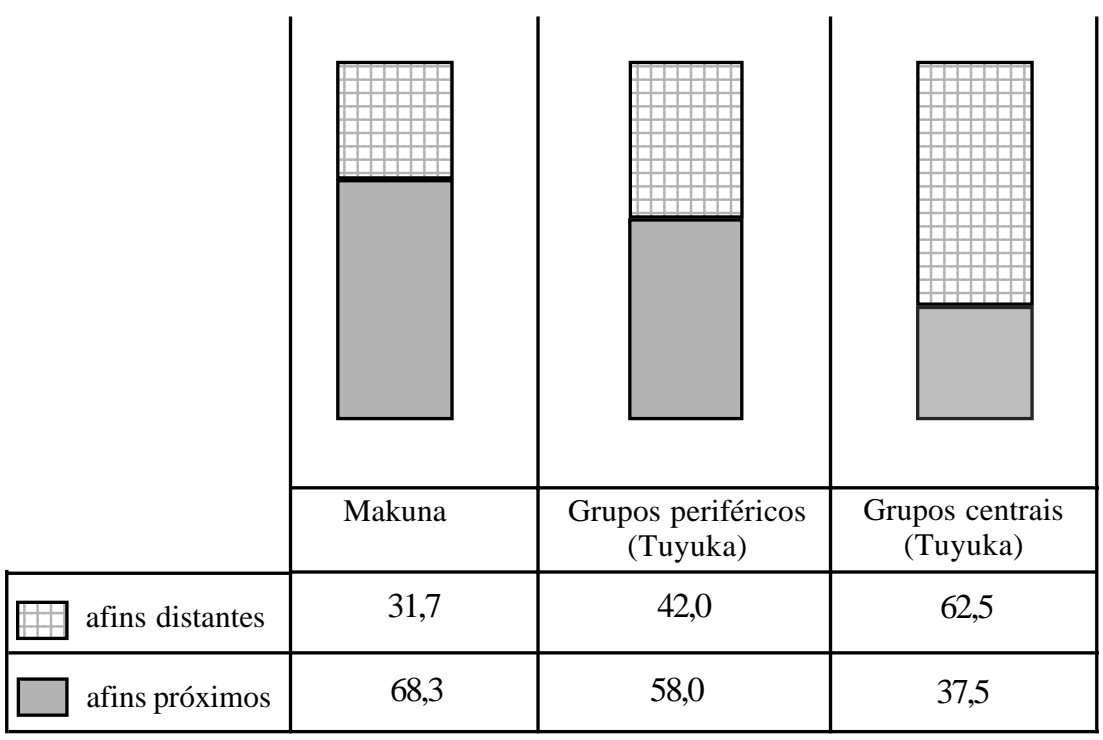

Gráfico 1: Proporção de afins próximos e afins distantes entre os Makuna e os Tuyuka (conforme números absolutos apresentados no Quadro 1).

Ainda que estes dados possam ser considerados circunstanciais e sujeitos a variações, eles indicam claramente a necessidade de elaborar mais minuciosamente o jogo que se dá entre os princípios da descendência e da afinidade como estruturadores de diferenças dentro dos nexos regionais (do tipo centro/periferia). Se as alianças entre malocas próximas espacialmente são tão importantes, como afirma Århem, o que dizer de grupos locais cujos moradores casam-se com mulheres de longe, comoé a tendência em alguns contextos tuyuka? Voltamos à associação entre a exogamia e o princípio da descendência, por um lado, e a endogamia e o princípio da aliança, por outro. Em outras palavras, grupos locais baseados em relações agnáticas dependem menos dos afins, distantes geográfica e socialmente, com os quais mantêm pouco contato. Distintamente da sociabilidade interna aos grupos locais que têm seus aliados próximos ou constituídos por relações cognáticas ${ }^{14}$. 
A análise estatística é utilizada aqui para abrir caminho para se investigar outras noções e práticas associadas aos idiomas da descendência ou da aliança. Tendo esta indicação, ainda que contingente, observa-se que várias outras características distinguem esses ambientes (centro e periferia) entre si. Os grupos locais periféricos são formados por segmentos de sibs de baixa hierarquia, ou que passam por um processo de forte dispersão, ou por segmentos de sibs de alta hierarquia mas em fases de depressão populacional ou dispersos por questões políticas ${ }^{15}$. Trata-se de grupos domésticos com maior mobilidade geográfica e menos tradição genealógica. Em geral desempenham papéis rituais secundários (como dos conhecidos "acendedores de cigarro" e "rezadores" do cigarro para o chefe).

Os grupos locais centrais são mais estáveis, sendo formados por parentes agnáticos próximos, em geral do mesmo sib; valorizam a memória genealógica e referências territoriais mais bem definidas, sendo, como consequiência, mais fixos. Em geral são grupos de mais alta hierarquia ${ }^{16}$, possuindo prerrogativas rituais, destacando-se seus povoados como centros rituais regionais ${ }^{17}$.

A relação entre os sibs tuyuka Ohpháia e Dahsiá é a que melhor expressa $\mathrm{o}$ aspecto hierárquico dessa distinção entre grupos centrais e grupos periféricos. Os últimos são os "servos" (empregados) tradicionais dos primeiros. Os Ohpháia afirmam que os Dahsiá "viviam por aî", em casas improvisadas ou agregados às suas malocas. A relação atual dos Tuyuka, de um modo geral, com os MAKU também é, neste aspecto, reveladora, guardando muitas semelhanças com a relação entre os dois sibs tuyuka mencionados. Os MAKU vivem em seus sítios, situados em pequenos igarapés em regiões interiores, chegam ocasionalmente para oferecer trabalho ou para trocar caça por farinha ou beijú e são considerados inferiores pelos Tuyuka.

Os casos de segmentos de sibs de mais alta hierarquia que transitam por essas áreas marginais são menos representativos. Em geral, sua localização nesses espaços é circunstancial e, quando não, decorre de rupturas mais graves e marcantes no seio do grupo de descendência (como acusações 
de feitiçaria com mortes). Enfim, trata-se de situações atípicas ou etapa de um processo de reestruturação de um grupo de parentes agnáticos.

Outros aspectos permitem uma caracterização mais completa desses ambientes sociais que constituem o nexo regional tuyuka do alto Tiquié. Um deles diz respeito aos diferentes tipos de casas existentes (ver Figura 1). O primeiro tipo de casa (basáriwi, em Tuyuka) é definido por construções maiores, grandes malocas com espaço interno que comporta rituais para os quais afluem pessoas de vários grupos locais da região. Por exigirem um considerável esforço coletivo na sua construção (transporte dos esteios e do caraná para a cobertura), em geral são erguidas por grupos de parentes agnáticos mais coesos e de menor mobilidade territorial. Trata-se de grupos locais de prestígio e que realizam ciclos rituais anuais, nos quais existe a caixa de adornos plumários (mapoátibá), usados nas "danças dos velhos" (bUtoábasá) e um cantor ou mestre de cerimônia (bayá) reconhecido. As grandes malocas são marcas dos grupos de mais alta hierarquia, aos quais cabe promover e coordenar as grandes cerimônias, inclusive as de iniciação masculina, nas quais se observa ampla participação dos Tuyuka da região e seus afins. Há inúmeros relatos, de viajantes e cronistas do século passado e início deste, de malocas que comportavam doze fogos ou mais. Essas malocas ainda são erguidas pelos Tuyuka, mas atualmente não servem como residência de todo o grupo local, mas apenas como casa cerimonial ou para moradia de um ou poucos grupos domésticos.

O segundo tipo de casa, chamado "casa de jacaré" (Usówi), é mais comum. Construção menos dispendiosa que a primeira, dispõe de espaço suficiente para a realização de rituais menores e é apropriada para um único grupo doméstico ou para, no máximo, três fogos (hearth family). Também havia desaparecido no lado brasileiro do rio Tiquié, mas agora está voltando a ser construída (em Fronteira foi erguida uma em 1995, para moradia de um grupo doméstico).

Jáo último tipo de casa, que os Tuyuka também chamam de waikaniyariwi, que poderia ser traduzido por "casa de pescador" (em alusão ao tipo de casa feita nos acampamentos de pesca), é muito comum hoje em dia e 
compõe a maior parte das casas dos povoados atuais. Em razão do contato, praticamente toda a população indígena da bacia do Uaupés e Içana, especialmente do lado brasileiro, passou a morar neste tipo de casa, em suas inúmeras variantes (casas com paredes de pau-a-pique, de casca de árvore batida ou de palha trançada, nos povoados das missões com tijolo e telha francesa ou de zinco, e assim por diante). Antes disso, porém, este tipo de casa, em sua versão mais simplificada, era construído por grupos domésticos pouco fixos, que, como dizem alguns Tuyuka, andavam sem paradeiro fixo (warukura basuka). Eram pequenos grupos que ora viviam com seus afins, ora em povoados de seu próprio grupo exogâmico, mas que compunham uma população flutuante e móvel.

Figura 1: Tipos de casas tuyuka

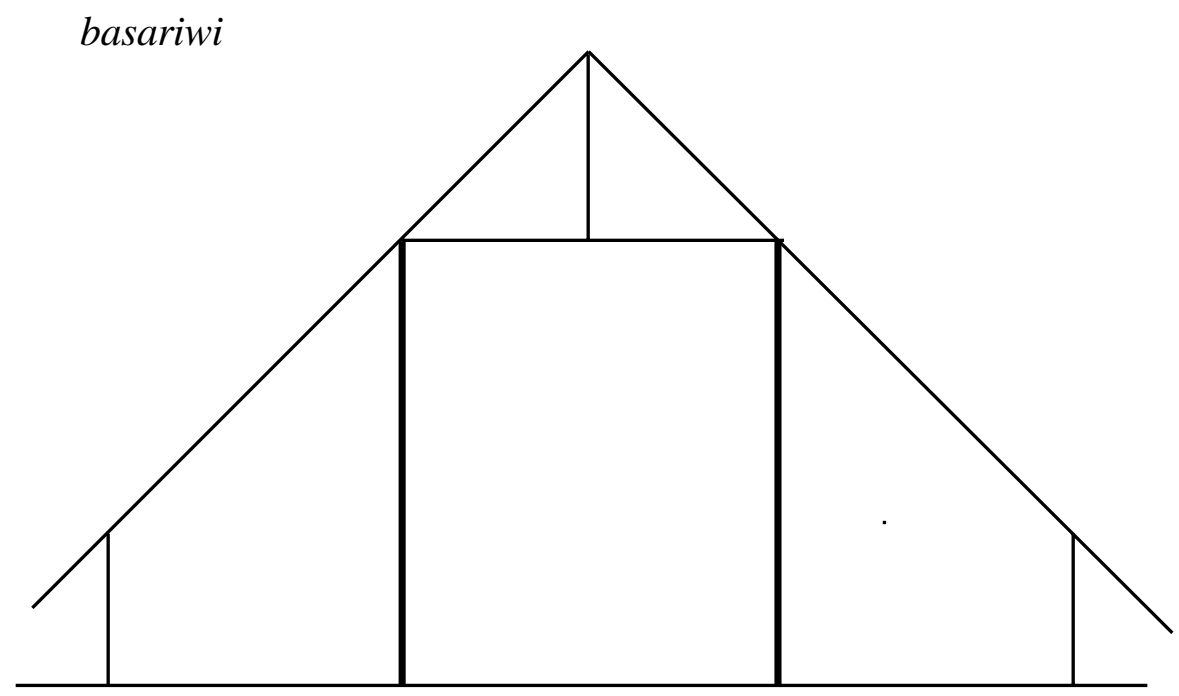

maloca grande, construída por chefes ou bayá, onde são promovidas cerimônias centrais 
ttsówi

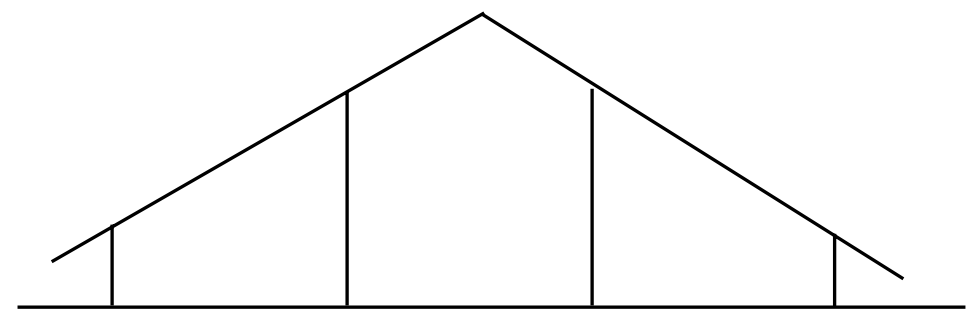

“casa de jacaré”, modelo intermediário, para poucos fogos

waikaniyariwi

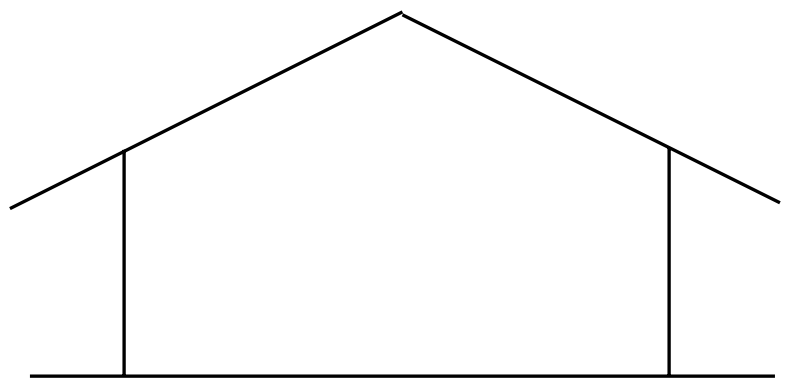

“casa de pescador”, termo também usado para casas provisórias estabelecidas em locais transitórios 
Atualmente, não são encontradas correspondências entre estes três estilos arquitetônicos e os grupos locais centrais e periféricos. Isto se deve às transformações da própria função da maloca no âmbito local, que passa de moradia coletiva de um grupo local coeso e com uma liderança capaz de mobilizar o trabalho para sua construção a casa comunitária, utilizada apenas nas festas e encontros comunitários. Estas formas arquitetônicas alternativas confirmam, no entanto, a abertura do sistema conceitual tuyuka às distinções entre grupos sociais, com claras conotações hierárquicas, e, como decorrência - embora não necessária-, para sua configuração em termos de grupos locais distintos.

Esta afirmação pode ser melhor compreendida levando-se em conta outro aspecto, a forma como os Tuyuka categorizam o espaço geográfico. Os Tuyuka têm como um modelo de classificação social, bastante usual, as áreas geográficas onde uma pessoa ou grupo reside, que são diferenciadas. Assim os seguintes termos são empregados:

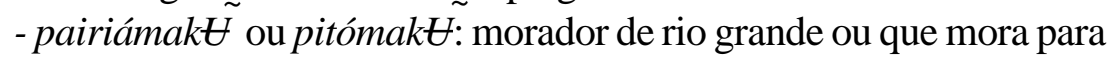
baixo, na direção da foz;

- potérimak $\forall$ : morador das cabeceiras;

- makár $\forall k \forall m a k \forall:$ morador de áreas mais interiores, em pequenos igarapés, no mato.

Em geral, a relação que se faz entre organização social e espaço entre os grupos TuKANo é aquela que supõe que sibs de alta hierarquia estariam localizados mais à jusante no rio do que os de baixa hierarquia, os primeiros mais próximos da foz e os últimos na direção das cabeceiras. Esta colocação, formulada por Christine Hugh-Jones, está apoiada em considerações cosmológicas que relatam a trajetória da sucuri ancestral que dá origem aos Barasana. É comum, parece-me que entre todos os povos TuKANO, a associação entre os segmentos do corpo desta cobra e a ordem hierárquica dos sibs, da cabeça ao rabo. Janet Chernela (1993) constata, entre os Wanana do médio Uaupés, que os sibs de mais alta hierarquia dominam locais onde há maior disponibilidade de recursos protéicos (cachoeiras e igapós mais abundantes de peixes). 
No caso dos Tuyuka do alto Tiquié, o eixo do rio não influencia na disposição espacial dos sibs e de seus segmentos. Isto não significa que as oposições foz/cabeceiras, rio grande/igarapé, rio/floresta não sejam fundamentais ao sistema de categorização social dos Tuyuka. Estão refletidas nas estratégias matrimoniais, por exemplo ${ }^{18}$. Em territórios mais consolidados (áreas de ocupação mais antiga), a distinção foz/cabeceira pode dar lugar àquela entre rio grande/igarapé, que já é um parâmetro para a relação TUKANo/MAKU no espaço.

\section{Conclusão}

Esta proposta de interpretação da organização sócio-espacial dos Tuyuka do alto Tiquié se inscreve no conjunto de estudos das formas de organização social supralocal na região do Uaupés/Pirá-paraná. Deve-se destacar que na literatura etnográfica especializada são constantes as formulações a este respeito. Além das noções de "grupo de descendência simples" por C. Hugh-Jones e de "grupo de aliança local" por Århem, como mencionadas acima, há ainda a formulação de "fratria" por Goldman. Esta última converge com algumas das idéias aqui expostas. Segundo o autor, a fratria é o ambiente onde se difundem mecanismos de group-binding: exogamia, ciclos de caxiris e formas de participação cerimonial ${ }^{19}$.

A relevância desta discussão no âmbito da etnologia do noroeste amazônico está na tentativa de entender uma situação regional específica do ponto de vista comparativo, manejando conceitos empregados em outros estudos desta área, e dando maior espaço a significados políticos, rituais, geográficos. Trata-se de tendência já consolidada na etnologia amazônica, como demonstra Viveiros de Castro (1993).

Tendo em vista os dados sobre os Tuyuka descritos acima, é possível sugerir um modelo de representação da organização sócio-espacial do alto Tiquié, considerada a concorrência entre os princípios da descendência e da aliança. Trata-se de um modelo concêntrico, baseado na distinção entre grupos locais que formam um ambiente central e grupos locais situados em sua periferia. Observam-se áreas em que predominam relações sociais 
estruturadas sobretudo no agnatismo e, à medida que daí nos afastamos, encontramos situações cognáticas, nas quais ocorre a convergência entre vários grupos de descendência, em geral afins entre $\mathrm{si}^{20}$.

Neste sentido, é mais adequado, em lugar da noção de "território", empregar o conceito de nexo regional, no intuito de evitar a idéia de uma exclusividade de determinado grupo de descendência. Considerando que as bacias do Uaupés/Pirá-paraná constituem um mosaico de situações sociais estreitamente conectadas, sugere-se aqui que no âmbito desse extenso sistema social existam regiões em que faz sentido pensar numa organização centro/periferia ${ }^{21}$. Os nexos regionais possuiriam núcleos (formados por um número variado de grupos locais) que se caracterizam como espaços da descendência, onde se resguardam identidades lingüísticas particulares e práticas rituais que atualizam relações hierárquicas. O caso do alto Tiquié é apropriado para pensar este modelo.

Nesse contexto, a noção de nexo regional procura, por um lado, dar conta de como aliança e descendência estruturam espaços particulares e, por outro, evidenciar que tal sistema só é possível na medida em que faz parte de um universo social mais amplo, com o qual está conectado e que o engloba.

\section{Agradecimentos}

Agradeço a leitura e comentários de Dominique Buchillet, Flora Cabalzar e Stephen Hugh-Jones, além das sugestões dos dois pareceristas desta Revista, que muito contribuíram para o aperfeiçoamento do texto.

\section{Notas}

1 Quando se trata da família lingüística, será usada no texto a palavra grafada em caixa alta, como Tukano e Maku. Tukano é usado para simplificar Tukano Oriental. Tukano, distintamente, diz respeito a um grupo de descendência específico. 
2 Neste ensaio, o termo grupo local é empregado para designar uma unidade social separada geograficamente, seja ela constituída por uma ou mais casas. Algumas vezes a palavra povoado é usada alternadamente, com o mesmo sentido. Como veremos mais adiante, o termo grupo local é empregado em outro sentido por Århem (1981).

3 O povoado de São Pedro (ver Mapa 1), por exemplo, tem quase um quarto de sua população formada por afins, representados por dois grupos domésticos makuna (yeba-mas ᄀ). Além disto, as próprias ligações entre os Tuyuka deste povoado, especialmente entre aqueles que são de diferentes sibs, são fortalecidas ou mesmo viabilizadas pelas relações com afins comuns. Tendo em vista esta situação, supõe-se que naqueles grupos locais em que a proporção de afins sobe para 40\% (como Bella Vista, Los Angeles e Belém, povoados "tuyuka" do lado colombiano), a força das alianças como fator de coesão também deva ser maior.

4 Como é o caso da região delimitada pelo Canõ Abiyú e pelo trecho do rio Tiquié acima da foz deste igarapé. Nesta área convivem os Tuyuka e os Bará, formando povoados constituídos por grupos domésticos das duas origens, como Bella Vista e Trinidad.

5 "The Barasana and Taiwano, who share a common language and intermarry with other language units, also intermarry amongst themselves as distinct patrilineal descent groups" (1979: 24).

6 A noção de specialist role surge da definição de um "grupo exogâmico simples", que é um conjunto de cinco sibs ordenados hierarquicamente, cada um dos quais associado a uma função determinada, do mais alto para o mais baixo nível, como de chefe, cantor (bayá), guerreiro, xamã e servo (HughJones, 1979 a). Neste contexto, ocorre uma complementação funcional em diferentes esferas do parentesco agnático.

7 Århem adota a idéia de Kaplan (1975) a respeito da aliança diacrônica, ou seja, a tendência de grupos sociais perpetuarem seus laços de afinidade por várias gerações, como resultado da ênfase em casamentos com afins próximos genealogicamente (1981: 194). 
Revista de Antropologia, São Paulo, USP, 2000, v. 43 nº 1.

8 Neste sentido, Århem afirma: "The local alliance group, in short, takes on the corporate character and functions usually associated with the unilineal descent group. Among the Makuna, access to and control over local women (...) provides the basis for the formation of corporate social groups above the level of the residence unit. The principle of symmetric marriage alliance here serves to define rights in the corporate property, constituted by the pool of local women as a productive and reproductive resource" (1981:212-3).

9 "The minimal segment corresponds to a situation in which the common ascendant of the youngst members of the group is a father" (ibid.: 226).

10 Os MAKU, embora também possuam um regime de descendência patrilinear, diferem dos grupos TUKANO por não considerarem a regra de exogamia local ou lingüística. Deste modo, formam grupos locais baseados em parentelas cognáticas e que estão em um permanente processo de mudança em sua constituição. Os grupos MAKU vivem nas regiões de interflúvio, ao passo que os grupos TUKANo se situam nas margens dos rios maiores (a respeito da relação entre os Tuyuka e os MAKU, ver Cabalzar, 1995: 87-90).

11 A este respeito, Viveiros de Castro (1993:158), em sua revisão dos estudos sobre organização social e parentesco nas terras baixas sul-americanas, chama a atenção para as limitações de um foco exclusivo sobre o parentesco, afirmando que "a sociologia da Amazônia não pode limitar-se a uma sociologia do parentesco (ou à sua mera "sublimação" cosmológica) porque o parentesco é limitado e limitante ali”.

12 Provenientes de autores nativos, como em Umúsi Pãrõkumu e Tõrãmu Kehíri (1995 [1980]), e fontes citadas por Béksta (1988).

13 Hugh-Jones usa consangüinidade no sentido de cognação, como definido por Viveiros de Castro (1993: 166 e 198-199, nota 14), isto é, no sentido sociológico/cultural, e não pelo terminológico/categorial.

14 Evidentemente este tipo de associação tem suas limitações. Embora a relação entre distância espacial e social seja constante, ela sofre uma série de inflexões (conflitos, disputas e rupturas das alianças) que limita seu uso. Outra 
variável é o histórico de cada relação, como casamentos que ocorreram em momento de proximidade entre grupos domésticos que posteriormente voltaram a se afastar.

15 Não são apenas os sibs e segmentos de sibs de baixa hierarquia que ocupam essa área marginal; também são encontrados segmentos de grupos de descendência mais prestigiados, de mais alto nível hierárquico (Hugh-Jones, 1979 a: 25, para o caso dos Barasana, e Cabalzar, 1995: 124-8). Por último, este ambiente também se constitui de pequenos grupos que sobreviveram de sibs antes maiores e que se reúnem formando, em alguns casos, grandes povoados ou ao redor de um chefe importante, de prestígio político e ritual. Trata-se, nesses casos, de grupos que não se referem mais a sib-centers, tomando emprestado o termo de Goldman (1963: 27).

16 Por exemplo, dois dos grupos locais centrais (Cachoeira Comprida e Pupunha) correspondem a segmentos do sib Ohpháia, o de mais alta hierarquia dos Tuyuka do Tiquié; e a população do terceiro povoado (Fronteira) também é constituída em sua maior parte por pessoas deste $s i b$, com a exceção de dois grupos domésticos Miñó.

17 Cachoeira Comprida e Pupunha são centros rituais de considerável importância, onde, periodicamente, ocorrem prestigiados rituais para os quais afluem pessoas dos povoados vizinhos, onde há a caixa de adornos plumários usados nas cerimônias principais ("dança dos velhos") e contam com um mestre de cerimônia e um rezador respeitados.

Em Bella Vista e em São Pedro também existem caixas de adornos plumários e, no primeiro, mora um grande bayá, reconhecido por todos os Tuyuka do Tiquié. Em São Pedro, estão morando os dois homens de mais alta hierarquia dentre os Tuyuka do Tiquié, mas que compõem apenas dois dos 14 grupos domésticos que formam este povoado. Porém, as exceções constituídas por estes dois grupos locais devem ser relativizadas:

1) o primeiro segmento do sib Ohpháia (que detém a posse e a prerrogativa de uso dos paramentos rituais) não reconhece São Pedro como seu local ideal, expressando inclusive uma certa aspiração em voltar para a região onde viviam seus avós, compreendida entre os povoados atuais de Fronteira e Pupunha;

2) o chefe e "dono" da caixa de adornos de Bella Vista também é do sib Ohpháia, e passou a viver no interior do igarapé onde está situado este povoado depois de desavenças com seus parentes de Pupunha, até hoje há contestações a respeito de suas prerrogativas sobre tais adornos. 
18 Os homens dos sibs tuyuka de mais alta hierarquia dirigem sua preferência para mulheres tukano, principalmente aquelas de nível hierárquico próximo, que moram abaixo dos Tuyuka no mesmo rio Tiquié. Justamente o contrário ocorre com aqueles de sibs de mais baixa hierarquia, que se casam especialmente com mulheres bará e makuna, que vivem na região das cabeceiras do Tiquié e em afluentes menores.

Em outro trabalho em preparação, será demonstrado, estatisticamente, a interferência do viés geográfico nas relações de casamento. Serão utilizadas informações sobre casamentos de quase todo o rio Tiquié, baseadas em registros de casamentos da missão de Pari-Cachoeira.

19 Segundo Goldman (1963: 288), "in the orbit of the phratry, the bonds are more impressively substantial, based as they are upon tradition, upon the fiction of blood kinship, and upon contiguity, hospitality, and cerimonial participations".

20 A região do alto Tiquié é exemplar neste aspecto, para onde convergem as cabeceiras de vários igarapés, como o Inambú e o Komeyá, configurando uma zona de interseção das "periferias" dos territórios de diversos grupos de descendência, como dos Bará do alto Tiquié e Inambú, dos Makuna do alto Komeyá e igarapé Castanha, dos Tukano à montante de Pari-Cachoeira e dos próprios Tuyuka.

21 Em outro trabalho em preparação (ver nota 18), será verificada a possibilidade de estender este modelo da morfologia tuyuka para outras situações regionais do mesmo rio Tiquié.

\section{Bibliografia}

ÅRHEM, K.

Makuna Social Organization: A Study in Descent, Alliance, and the Formation of Corporate Groups in the North-Western Amazon, Uppsala Studies in Cultural Anthropology, Stockholm, Almqvist \&Wiksell. 
1989

"The Makú, the Makuna and the Guiana System: Transformation of Social Structure in Northern Lowland South America", Ethnos, vol. $1-2: 5-22$.

BÉKSTA, C.

1988

A maloca tukano-dessana e seu simbolismo, Manaus, SEDUC/AM.

CABALZAR, A.

1995 Organização Social Tuyuka, São Paulo, dissertação, Universidade de São Paulo.

1999 "O templo profanado: missionários salesianos e a transformação da maloca tuyuka", in WRIGHT, R. (org.), Transformando os Deuses. Os múltiplos sentidos da conversão entre os povos indígenas do Brasil, Campinas, Editora da UNICAMP.

\section{CHERNELA, J.}

1993 The Wanano Indians of the Brazilian Amazon. A Sense of Space, Austin, University of Texas Press.

GOLDMAN, I.

1963 The Cubeo. Indians of the Northwest Amazon, Urbana, The University of Illinois Press.

HUGH-JONES, C.

1979a From the Milk River. Spatial and Temporal Processes in the Northwest Amazon, Cambridge, Cambridge University Press.

HUGH-JONES, S.

1979 b The Palm and the Pleiades. Initiation and Cosmology in Northwest Amazonia, Cambridge, Cambridge University Press. 
"Clear Descent or Ambiguous Houses? A Re-Examination of Tukanoan Social Organization", L'Homme, vol. 126-128(XXXIII): 95-120.

1995 "Inside-out and back-to-front: the androgynous house in Northwest Amazonia", in CARSTEN, J. \& HUGH-JONES, S., About the House. Lévi-Strauss and beyond, Cambridge, Cambridge University Press.

\section{JACKSON, J.}

1983 The Fish People, Cambridge, Cambridge University Press.

KAPLAN, J.

1975

The Piaroa. A People of the Orenoco Basin, Oxford, Clarendon Press.

KOCH-GRÜNBERG, T.

1967 [1909] Zwei Jahre unter den Indianern. Reisen in Nordwest-Brasilien -19031905, 2 vol., Graz, Akademische Druck- u. Verlagsanstalt.

1913

"Betóya-Sprachen Nordwestbrasiliens und der angrenzenden Gebiete", Anthropos, IX, Nr 7.

NIMUENDAJÚ, C.

1950

"Reconhecimento dos rios Içana, Ayarí e Uaupés. Relatório apresentado ao Serviço de Proteção aos Índios do Amazonas e Acre, 1927”, Journal de la Société des Americanistes de Paris, vol. 39: 125-83.

RICE, $\mathrm{H}$.

1910

“The River Uaupés”, The Geographical Journal, vol. XXXV(6): 682700 .

SORENSEN, A. P.

1967

"Multilingualism in the Northwest Amazon", American Anthropologist, vol. 69(6). 
UMUSI PÃRÕKUMU \& TÕRÃMU KEHIRÍ

1995

Antes o mundo não existia, São Gabriel da Cachoeira, UNIRT/FOIRN.

VIVEIROS DECASTRO,E.

1993

"Alguns aspectos da afinidade no dravidianato amazônico", in VIVEIROS DECASTRO, E. \& CARNEIRODA CUNHA, M., Amazônia. Etnologia e História Indígena, São Paulo, Núcleo de História Indígena e do Indigenismo - USP/FAPESP.

\begin{abstract}
Considering the present situation of research about the Northwest Amazon social organisation, this paper proposes a way of understanding how relations based on patrilineal descent and alliance are articullated and spatially organised among the Tuyuka uf upper Tiquié River (Uaupés basin). The model drawed is fundamented on distinctions between two forms of local groups, that constitute a regional nexus with center and periphery. This model allows the understanding of a uaupesian social system with areas where predominate values based on agnatism, commom language and exogamy, and how these areas are inter-connectec.
\end{abstract}

PALAVRAS-CHAVE: Tuyuka indians - social organisation, Tuyuka indians - Eastern Tukanoan, Tiquié river - Uaupés/Pirá-paraná system - Northwest Amazon.

Recebido em dezembro de 1999. 